\title{
Chemotherapy Dosing Part I: Scientific Basis for Current Practice and Use of Body Surface Area
}

Sewell, GJ

http://hdl.handle.net/10026.1/3714

10.1016/j.clon.2006.10.010

Clinical Oncology

Elsevier BV

All content in PEARL is protected by copyright law. Author manuscripts are made available in accordance with publisher policies. Please cite only the published version using the details provided on the item record or document. In the absence of an open licence (e.g. Creative Commons), permissions for further reuse of content should be sought from the publisher or author. 


\title{
Overview
}

\section{Chemotherapy Dosing Part I: Scientific Basis for Current Practice and Use of Body Surface Area}

\author{
S. A. Kaestner*, G. J. Sewell $†$ \\ "Department of Pharmacy and Pharmacology, 5W, University of Bath, Claverton Down, Bath BA2 7AY, UK; †Department of \\ Pharmacy, Kingston University, Penrhyn Road, Kingston upon Thames, Surrey KT1 2EE, UK
}

\begin{abstract}
:
Cytotoxic chemotherapy is characterised by a low therapeutic index and significant variability in therapeutic and toxic effects. In an attempt to reduce this variability, most chemotherapy doses are individualised according to patient body surface area (BSA). This practice, which was introduced almost 50 years ago, clearly has practical and economic implications for the healthcare system. Furthermore, the clinical value of this approach has, in recent years, been questioned. Despite established practice, chemotherapy dose selection remains complicated, partly because treatment effects are difficult to measure, partly because drugs are used in combination with other treatment modalities, and also because the patient's condition may change with disease progression. Various patienț-related factors can affect drug pharmacokinetics (PK) and pharmacodynamics (PD), for example organ function, expression and activity of metabolising enzymes, drug resistance, body size, gender, age, concomitant disease and co-administration of other drugs. These factors may be of clinical significance in chemotherapy dose determination and measures of PK, PD or both feature in attempts to devise more rigorous methods for chemotherapy dosing. Part I of this series of two reviews describes the history and clinical impact of BSA-based chemotherapy, and examines the scientific evidence to support BSA dosing. It evaluates the factors affecting PK and PD for specific drugs that could inform and refine dose determination. Kaestner, S. A., Sewell G. J. (2006). Clinical Oncology 19, 23-37
\end{abstract}

(C) 2006 The Royal College of Radiologists. Published by Elsevier Ltd. All rights reserved.

Key words: Body surface area, cancer, chemotherapy, dose, pharmacokinetics, variability

\section{Introduction and Information Gathering}

Part I of this review series focuses on the limitations of the current practice used for dose determination. Some of the complexities of chemotherapy dose selection are discussed in the initial sections reviewing the prediction of the clinical effects of cytotoxic drugs and the variability associated with cytotoxic chemotherapy, in terms of exposure of tumour and normal tissues to drug, and also in tumour response. The origin of body surface area (BSA) dosing and its rationale in the calculation of cytotoxic doses is considered in the light of both historical and current evidences, together with published information on the actual effect of BSA dosing on the variability of drug exposure. Factors giving rise to potential variability in the exposure of tissues to drug despite BSA-based dosing strategies, including patient-specific, clinical, pharmacokinetic (PK)- and pharmacodynamic (PD)-related factors, are used to illustrate the inherent limitations of BSA dosing.

A comprehensive literature search was carried out to identify relevant publications in Embase (1980 to present), PubMed (1966 to present), and Web of Science (1981 to present). The search terms used were 'chemotherapy dose body surface area pharmacokinetics' and 'chemotherapy dose strategy cancer'. Internet-based and manual searches were also carried out to identify any key references from the 'grey' literature.

\section{Cytotoxic Drug Dosing: Limitations of Current Practice}

The optimal cytotoxic drug dose should give a maximal anti-tumour effect with acceptable levels of toxicity. In clinical practice, cytotoxic drugs frequently cause toxic effects that would be considered unacceptable in the treatment of non-malignant disease. Although toxicity is commonly regarded as the most important effect to control, partly because it is easier to measure, the risk of under-dosing and reduced efficacy must also be considered. In clinical practice it is more common to reduce doses, increase dose intervals, or skip courses in response to adverse effects than it is to increase the dose intensity in cases where treatment is well tolerated and there is no significant toxicity. This approach may reduce the severity of toxic effects, but it could also result in a suboptimal therapeutic effect [1-6]. For example, trials on adjuvant cyclophosphamide, doxorubicin and 5-fluorouracil (CAF) in breast cancer have shown that under-dosing may lead to an almost $20 \%$ relative reduction in disease-free survival [7]. 
Similarly, Bonadonna et al. [8] observed an even larger survival reduction in patients receiving less than $85 \%$ of cyclophosphamide, methotrexate and 5-fluorouracil (CMF) target doses.

\section{Predicting the Clinical Effects : of Cytotoxic Drugs}

The ability to predict the clinical effect of a given drug dose, either by direct or surrogate measures, is a prerequisite for developing robust dose strategies.

\section{Pharmacokinetic Measures and Toxicity}

Difficulties in measuring the clinical effects of cytotoxic drugs have resulted in the use of surrogate markers [9]. These include PK measures and levels of toxicity, both with advantages and limitations [10]. Surrogate markers have the advantage of being clinically measurable, and although relationships with clinical effect have been observed for a number of drugs, they may also be absent or limited to specific tumour types [1,10-13]. An example of a PK-effect relationship is that for carboplatin, where area under the plasma concentration-time curve (AUC) values above $5-7 \mathrm{mg} / \mathrm{ml} \times \mathrm{min}$ do not give any significant increase in the likelihood of tumour response, but result in increased toxicity $[14,15]$. Other drugs for which relationships have been reported between both PK measures and toxicity and therapeutic effect, in specific cancer types, include methotrexate, 5-fluorouracil (5-FU), etoposide and cisplatin [16-19]. In a study including patients with different cancer types, the AUC for free cisplatin and the level of cisplatin DNA adducts in healthy tissue, quantified in white blood cells and expressed as the area under the DNA adduct curve, were significantly higher in responders than in nonresponders, as judged by tumour response after six courses [19]. However, results such as these have to be interpreted with caution. The relevance of measuring DNA adducts in white blood cells, which are immediately and continuously exposed to the drug, to predict levels of DNA adducts in tumour cells must be questionable.

The most common relationship studied is that between PK and toxicity. In addition to the drugs mentioned above, relationships between these measures have been observed, for example, for topotecan, irinotecan (and its metabolite $\mathrm{SN}-38)$, doxorubicin and epirubicin [14,19-26]. In most cases, the only quantitatively measurable toxic effects are leukocyte or thrombocyte nadir counts. However, differences in pharmacological sensitivity between healthy tissue and tumour tissue may limit the value of using these 'levels' of toxic effects as predictive measurements of antitumour effect. Also, toxic effects may, like clinical effects, be time dependent and affected by prior or concomitant treatment, including colony-stimulating factors and/or scheduling and administration route $[27,28]$. For example, patients previously treated with cytotoxic drugs often have a lower bone marrow reserve than untreated patients $[2,14,29]$. Overlapping toxic effects for drugs in combination regimens can also be a problem, as it is not possible to apportion the contribution of each drug to the incidence or severity of a specific toxic effect. In addition, absolute neutrophil counts or neutrophil survival fractions may not reflect the time course of neutropenia, and this time course may be significant when comparing different patients or different drugs. The duration of toxicity is important, because patients with prolonged neutropenia are at greater risk of infection than patients who might have developed the same neutrophil nadir, but recover faster $[20,30]$. Time courses of haematological toxicity have been considered, for example, for topotecan lactone, epirubicin, and the epirubicin-docetaxel combination, with the purpose, in the latter case, of predicting the day of nadir and duration of leukopenia in breast cancer patients $[20,31,32]$.

There are, however, also some additional factors that complicate or limit the value of PK measures as surrogate markers for drug effects. PK measures calculated from drug or metabolite concentrations in plasma, saliva, urine or faeces may (like drug levels in target tissue) not be related to the cytotoxic drug therapeutic effect. Also, drug levels in healthy tissue do not necessarily reflect those in the target tumour tissue. Potential design flaws in PK studies include non-standardised administration duration, the failure to measure all pharmacologically active drug degradants or metabolites (particularly in the case of pro-drugs), or the collection of blood samples at incorrect times or for an insufficient number of time points. For drugs with circadian PK, sampling becomes even more complex $[2,33,34]$. It is also important to select the appropriate PK measures to study. As mentioned above, if relationships exist between PK measures and drug effects, these are often drug and tumour type specific. For some drugs, total exposure (AUC) may be important for anti-tumour effect, whereas for others the peak plasma concentration $\left(C_{\max }\right)$ or the area under the first-moment vs time curve may give more predictable relationships $[1,35,36]$. In many cases, the duration above a certain plasma concentration (the usually unknown target concentration) is probably of significance, and may affect distribution to the target tissue $[37,38]$. A further complication with the use of PK measures is the variation in PK with patient age [39]. The use of PK measures as surrogate markers also has ethical and financial considerations relating to patient discomfort and inconvenience of multiple blood sampling, and the additional time and costs incurred, respectively. Bioanalytical methods used in PK studies require extensive validation, which is costly and time consuming [40,41]. These issues are considered further in Part II of this review series, in sections describing the use of both PK and toxicity for dose individualisation [42].

\section{Key Points}

- PK and toxicity markers are attractive surrogates of therapeutic response as they can be easily measured.

- However, the absence of relationships between surrogate markers and therapeutic outcome, together with various confounding factors, severely limits their clinical application. 


\section{Measurement of Tumour Response and Tumour Drug Concentrations}

The measurement of the therapeutic response to cytotoxic drugs is a difficult challenge. The clinical assessment of tumour response is not particularly useful in dose modification, because there is often a significant time-lag between dosing and the expected anti-tumour effect [43]. The direct measurement of drug concentrations in tumours is also of little value, partly because of practical and ethical considerations and also because of tumour heterogeneity. Tumour drug concentrations and residence times $\left(t_{1 / 2}\right)$ do not give clear indications of tumour response and are unlikely to be homogenous across the tumour mass $[44,45]$. Tumours are often poorly vascularised and have a limited blood perfusion, resulting in a reduced rate of drug penetration compared with many of the organs subject to drug toxicity, for example bone marrow, heart and kidneys [45-49]. Tumour blood flow may exhibit circadian variation and a large inter-patient variability, and can also differ across the same tumour, with inner masses being poorly perfused and exposed to lower amounts of drug $[2,33]$. Tumour and healthy tissue PK have, for example, been studied for $5-\left[{ }^{18} \mathrm{~F}\right]$-fluorouracil using ${ }^{18} \mathrm{~F}$-positron emission tomography combined with plasma PK. The initial 5-FU extraction from plasma into liver was observed to be 205-fold higher than 5-FU extraction by gastrointestinal tumours. Also, 5-FU plasma catabolites, for example $\alpha$-fluoro- $\beta$-alanine (FBAL), accounted for $83 \%$ of tumour exposure [47].

Other factors that influence the drug concentration in tumour cells include the composition of the extracellular matrix and the rate of diffusion through tissue, drug resistance and drug metabolism $[44,50,51]$. For example, it has been suggested that saturation of intra-tumoural dihydropyrimidine dehydrogenase (DPD), the main catabolic enzyme for 5-FU, leads to the accumulation of 5-FU in tumours after the administration of the pro-drug capecitabine [48]. Finally, care must therefore be taken to measure the active cytotoxic species in tumours, which in many cases will be metabolites rather than the parent drug. Factors influencing exposure of tumour and normal tissues to drug are considered in detail later in this review.

\section{Estimation of Tumour Drug Concentrations by Indirect Methods}

Ethical and practical limitations, described above, preclude the direct measurement of tumour drug concentrations. Therefore, indirect approaches have been used to estimate tumour drug concentrations and predict tumour response. These include, for example, the development of physiologically based PK hybrid models, in which pre-clinical models are scaled to predict human tumour drug concentrations. One approach to this is to use a forcing function, describing the human plasma drug concentration-time profile, linked to a model describing drug disposition in tumours, derived from both animal and human data [37]. Examples of such models include those for topotecan, carboplatin and temozolomide, for which estimated ratios between AUC values for tumours and plasma (AUC tumour $_{\text {I }}$ $A U C_{\text {plasma }}$ ) were studied to predict the relative drug uptake into tumours [37]. One disadvantage in this approach is the assumption that drug pharmacodynamics (PD) are equivalent in animals and humans. Other non-invasive methods in the study of tumour drug levels include in vivo ${ }^{19} \mathrm{~F}$-nuclear magnetic resonance spectroscopy and ${ }^{18} \mathrm{~F}$-positron emission tomography, which have been used as imaging methods for 5-FU in human tumours [52-57], and gamma camera imaging of ${ }^{195 \mathrm{~m}} \mathrm{Pt}$-cisplatin and ${ }^{195 \mathrm{~m}} \mathrm{Pt}$-carboplatin in animals [58]. Presant et al. [52] estimated the tumoural half-life $\left(\mathrm{t}_{1 / 2}\right)$ of 5 -FU with ${ }^{19} \mathrm{~F}$-nuclear magnetic resonance spectroscopy, and reported an association between tumour trapping, defined as an intra-tumoural 5-FU $\mathrm{t}_{1 / 2} \geq 20 \mathrm{~min}$, and response, during 5-FU treatment with or without folinic acid. However, the patients in this study had different tumour types and treatment histories, so tumour trapping was probably not the only predictive factor of response. Also, of the patients only receiving $5-\mathrm{FU}$ or 5 -FU/folinic acid, the numbers that could be evaluated at the time of publication were 5 of 15 who showed trapping, and 18 of 31 with no trapping. In the later Southwest Oncology Group study (SWOG 9006) [59], including only patients with gastrointestinal cancer, tumour trapping had no statistically significant effect on response or progression-free survival. However, this study may have been inadequately powered to identify any relationship, and so the importance of tumour trapping remains unclear.

Both direct and indirect methods to determine tumour drug concentrations or localise drugs to tumour tissue may, however, be of questionable value in evaluating the pharmacological effect of a cytotoxic drug, particularly in advanced metastatic disease. However, hybrid PK models may be useful in establishing the significance of different factors, such as drug metabolism and drug diffusion through healthy and tumour tissues, to tumour drug distribution.

\section{Variability in Tumour Response}

In addition to differences in drug exposure between tumour cells, the heterogeneous composition of tumours may give different intra-tumour responses to a given drug concentration, resulting in a variable cytotoxic effect $[44,45]$. A tumour can contain apoptotic/necrotic cells, cells from different tissue types, and cells originating from the same tissue type, which have differentiated in various ways and subsequently exhibit different characteristics [60]. Tumour cells also frequently exhibit either intrinsic or acquired resistance to a drug, or a range of drugs. Briefly, drug resistance can either be caused by a loss of sensitivity/ altered tumour response, or reduced exposure to the drug through efflux pumps, or both. In the first case, cellular mechanisms such as DNA repair are up-regulated [49] or insufficient perfusion, and consequently reduced levels of oxygen and nutrients, may induce changes in cell metabolism and the cell cycle, as well as drug sensitivity $[2,49]$. In the second case, ATP-binding cassette (ABC) transporter systems can result in drug efflux from tumour cells [61]. 
Some relevant issues relating to drug resistance will be considered later in this review.

\section{Key Points}

- Various factors influencing tumour drug exposure, including tissue composition and poor blood perfusion, often preclude clear relationships between drug concentrations in tumours and readily measurable drug concentrations in, for example, plasma or urine.

- For similar reasons, it is unlikely that drug concentrations will be homogenous throughout tumour tissue.

- Cells within a tumour probably exhibit different characteristics that influence the response to chemotherapy.

\section{Calculation of Cytotoxic Drug Doses - the Use of Body Surface Area}

In 1883, it was discovered that small animals utilised relatively more oxygen and produced relatively more heat than larger animals. These findings could be explained because smaller animals have relatively larger surface areas per unit mass, when compared with larger animals [62]. These observations were confirmed and applied to humans, giving rise to the practice of expressing human basal metabolism in terms of BSA rather than body weight (BW) [62]. Nearly 30 years later, correlations between blood volume and BSA were observed, and in the 1940s-1950s relationships were found between BSA and the total amount of circulating plasma proteins. The relationship between BSA and renal function was also considered, as the total number of glomeruli and kidney weight were found to be proportional to BSA for various mammals, and the ratios of kidney weight to BSA were similar for rat, dog, and man [62]. The Addis urea excretion rate (used as a measure of renal function) was in turn proportional to kidney weight, and consequently it was considered that there was a relationship between renal function and BSA [62]. In a more recent study, where glomerular filtration rate (GFR) was measured by ${ }^{99 \mathrm{~m}} \mathrm{Tc}$ diethylenetriamine-pentaacetic acid clearance in 122 patients, a clinically relevant correlation between BSA and GFR was considered unlikely [63]. Also, even if there is a weak correlation between GFR and BSA, this relationship would not be valid in cases of renal disease or renal failure. Initially, BSA was recommended in dosage calculations for intravenous fluids, electrolytes, drugs and blood replacement needs in children, as it gave better outcomes than dosing based on BW or age [64]. In the early days of cancer chemotherapy, anti-cancer drug doses were, however, either fixed or based on BW $[62,64,65]$. Prompted by publications by Pinkel [62] and Freireich et al. [66], recommending the use of BSA to extrapolate chemotherapy doses from animals to human phase I studies and for the dosing of patients, many paediatricians started using BSA for anti-cancer drug dosing, and they were followed by medical oncologists [64]. Pinkel [62] had evaluated published studies for appropriate therapeutic dose ranges for some cytotoxic drugs, including methotrexate, 6-mercaptopurine (6-MP) and actinomycin D. He then calculated doses per unit surface area, and unit BW, for representative members of different animal species and humans. The 'effective' dosages of several anti-cancer drugs were found to be similar among mammals when calculated per unit body surface, but widely divergent when calculated based on BW. There were, however, still large differences. For 6-MP, for example, the calculated doses were $85 \mathrm{mg} / \mathrm{m}^{2} /$ day for mice, $63 \mathrm{mg} / \mathrm{m}^{2} /$ day for infants and $108 \mathrm{mg} / \mathrm{m}^{2} /$ day for $70 \mathrm{~kg}$ human adults. Freireich et al. [66] retrospectively studied drug toxicity data from small and large animals, as well as from humans, and placed them on a 'reasonably' similar basis. Dosage information for different species was compared quantitatively, with all calculations based on a $60 \mathrm{~kg}$ man and average weights for the various animals, assuming that 'the average patient' received no additional therapy. In addition, administration methods and scheduling were often different between species. For some cytotoxic drugs, doses required to reach toxic end points (maximum tolerated doses in man and $\mathrm{LD}_{10}$ in animals) .were similar on a BSA scale. As an example, for mitomycin $C$, the BSA-adjusted doses were $7.4 \mathrm{mg} / \mathrm{m}^{2}$ for man, $5.1 \mathrm{mg} / \mathrm{m}^{2}$ for mouse and $7.4 \mathrm{mg} / \mathrm{m}^{2}$ for monkey. However, for $5-\mathrm{FU}$, the doses were less similar; $555 \mathrm{mg} / \mathrm{m}^{2}$ for man, $190 \mathrm{mg} / \mathrm{m}^{2}$ for $\mathrm{dog}$ and $93 \mathrm{mg} / \mathrm{m}^{2}$ for mouse, and in fact, the doses seem to have been more similar on a $\mathrm{mg} / \mathrm{kg}$ basis. Given these observations, it seemed reasonable to adopt BSA dosing for anti-cancer drugs at the time. However, in light of current knowledge, it seems unlikely that if dosing strategies were being developed today, BSA dosing would feature in cancer chemotherapy. First, inter-species differences in BSA are much larger than the differences in BSA between patients. Second, a large variety of factors known to be relevant for drug disposition, some of which will be discussed below, are not accounted for. In 1958, Pinkel [62] mentioned that 'one objection to the use of BSA is the variation in physical and chemical activities among various species, among different individuals within the same species, and in the same individual at different times'. Freireich et al. [66] commented that skin surface area was used, although it was 'unlikely that the skin is the target area of action of any particular drug', and they considered it more probable that the skin surface was more or less proportional to the true target surface. Also, they did point out that the evaluation of animal toxicity screening systems was used as a tool to enable the safe introduction of new drugs into man, and did not attempt to relate therapeutic doses in the various mammalian species. Alternative strategies for chemotherapy dose individualisation are discussed in Part II of this series [42].

Another problem with BSA dose individualisation is that BSA cannot be measured, but has to be estimated with formulae generally incorporating measures of BW and height. There is no clear evidence for the accuracy of BSA calculations, and the estimation of human BSA has been described as 'probably the most difficult of all anthropometric procedures' $[1,67]$. Different formulae tend to give 
significantly different surface areas for the same individual, partly because they were developed from individuals with different racial origins [67-69]. The customary approach in clinical practice is to calculate BSA using Du Bois and Du Bois' [70] height-weight formula:

Area $\left(\mathrm{cm}^{2}\right)=\mathrm{BW}(\mathrm{kg})^{0.425} \times$ height $(\mathrm{cm})^{0.725} \times 71.84$.

This was the formula with least error after iteration and graphical interpolation of data from nine subjects, who had been measured by moulds in a laboratory in 1916 [70]. Pinkel [62] used the Du Bois and Du Bois formula in his studies, but mentioned that it only gives a 'rough approximation' of BSA. Freireich et al. [66] suggested that the two-thirds power of weight $\left(\mathrm{BW}^{2 / 3}\right)$ was a sufficient and appropriate unit for estimating BSA. Some studies have suggested that the Du Bois and Du Bois formula predicts BSA with a systematic negative bias and might be invalid when BSA is below $1.3 \mathrm{~m}^{2}$ [69], whereas other studies controversially suggest that it overestimates BSA [71], or alternatively support the use of the formula [67]. Currently, there is no scientific evidence in favour of alternative formulae for BSA calculation $[67,68,72]$. Additionally, there is some controversy regarding the use of actual or ideal BW (IBW) for calculating BSA and it has been recommended that actual weight should be used, except for patients who are clinically obese ( $>30 \%$ overweight) [73]. Other reports do not support IBW-based empirical dose reductions in obese patients, although calculated doses can be as much as $15-30 \%$ higher if $\mathrm{BW}$, rather than IBW, is used to determine BSA. In the absence of recommendations, both are used, or sometimes an average between them [74].

Except for the inaccuracies inherent in methods for BSA calculation (Du Bois and Du Bois [70] estimated the maximal error as $\pm 5 \%$ ), there is a substantial risk of arithmetical errors. Errors in the use of dosage equations have been found to account for more than $15 \%$ of medication prescribing errors [75], and in BSA dosing there are two calculation steps. that may introduce errors. First, the patient's BSA has to be calculated, and this is dependent on the accuracy of weight and height measurements, and then the dose for that specific BSA is determined. The first calculation is often avoided as it is common to use nomograms to estimate the BSA, but the reliability of these nomograms also tends to differ [68]. In clinical practice, the calculated cytotoxic drug doses are also frequently manipulated by rounding to the nearest convenient dose $[1,76,77]$. Finally, for many cancer patients, body size will probably vary during the course of the disease, due to conditions such as cachexia and anorexia $[76,78]$. Despite this, BSA is not always re-calculated between treatment cycles, although there are recommendations that BSA should be re-calculated when BW has changed by more than $5-10 \%$ [73].

\section{Key Points}

- BSA dosing was introduced for cancer chemotherapy about 50 years ago, and was based mainly on retrospective inter-species toxicity studies.
- The estimation of BSA used in dosage calculations may be inaccurate.

- The rationale for BSA dosing strategies has not been supported by PK studies and pharmacological investigations.

\section{Effect of BSA Dosing on Variability in Drug Exposure}

Given the difficulties in measuring and interpreting intratumoural drug concentrations previously mentioned, most literature reports have focused on plasma $\mathrm{PK}$ as an indicator for drug exposure. Whether or not plasma PK measures are accurate or reliable surrogate markers for the clinical effects of a drug, they do reflect the distribution and elimination of drugs in the patient and should show some consistency between patients when a drug dose is assumed to be individualised, provided that the method for individualisation is reliable. However, available data suggest that BSA-based dosing fails to standardise the variability in cytotoxic drug exposure $[1,68,72,79-83]$ (see Table 1). Gurney et al. [31] conducted a study with the primary aim of evaluating any correlation between BSA and the clinical effects of epirubicin. The same epirubicin dose was given to 20 cancer patients, but no correlations were observed between either BSA or BW, and any PK measure or the severity of neutropenia. Similar results were obtained by Cosolo et al. [24], who found no correlation between epirubicin clearance and BSA. Dobbs and Twelves [84] also studied the effect of BSA dosing on epirubicin PK. In 32 women with advanced breast cancer, there was no significant difference between the coefficients of variation for unadjusted clearance vs BSA-adjusted clearance, whereas the coefficients of variation should have been less for the latter, if BSA was significant. Also, predictions based on a linear relationship between epirubicin dose and AUC indicated that BSA-unadjusted doses did not increase the variability in AUC, or have any effect on myelosuppression [84]. Although the BSA range for these patients was fairly narrow, the study was well designed to evaluate factors of importance for both PK and PD variabilities, as well as any relationships between the two.

For some drugs, fixed doses have been observed to give closer plasma drug levels than doses normalised for BSA [60]. However, the results are controversial. In a cross-over study comparing BSA dosing $\left(175 \mathrm{mg} / \mathrm{m}^{2}\right)$ and flat-fixed dosing $(300 \mathrm{mg})$ of paclitaxel given as a $3 \mathrm{~h}$ infusion, a reduced inter-individual variability in AUC was observed after the administration of BSA-based doses $[60,85]$. However, the percentages of total variation in AUC and clearance explained by BSA were similar to the percentages of total variation explained by $B W$, which is accounted for when estimating BSA. BW could therefore be the factor explaining much of the PK variability. Also, because no clear relationship between AUC and paclitaxel PD has been shown, AUC could be considered as a poorly selected PK measure to study [86]. Ranges of neutrophil nadir counts were not different between the BSA-dosed and fixed-dosed 
Table 1 - Examples of pharmacokinetic variability and relationships between drug clearance and body surface area (BSA) for a selection of chemotherapy agents

\begin{tabular}{|c|c|c|}
\hline $\begin{array}{l}\text { Drug } \\
\text { (dosing strategy) }\end{array}$ & $\begin{array}{l}\text { Inter-patient } \\
\text { variability } \\
\text { (CV) in } \mathrm{AUC}^{*}(\%)\end{array}$ & $\begin{array}{l}\mathrm{CL} \text { ys BSA } \\
\text { relationship }\end{array}$ \\
\hline
\end{tabular}

\section{Epirubicin}

BSA dosing

$\begin{array}{ccc}\text { [24] }(n=10) & 14 & P>0.05 \\ \text { [84] }(n=32) & 31 \dagger & r=-0.12 \\ \text { Flat-fixed dosing } & & \\ \text { [31] }(n=18) & 40 & r_{s}=0.2\end{array}$

Etoposide (fixed daily oral dose)

[26] $(n=50) \quad 64 \quad \begin{aligned} & \text { No relationship, but } \\ & r \text {-value not published }\end{aligned}$

\section{5-Fluorouracil (BSA dosing)}

$\begin{array}{ll}\text { [95] }(n=81) & 63\left(C_{\text {ss }}\right) \\ \text { [99] }(n=34) & 30\end{array}$

Topotecan (BSA dosing, oral)

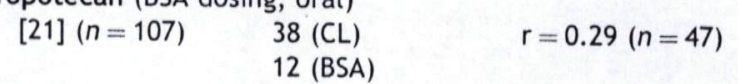

Cisplatin (BSA dosing)

$\begin{array}{ll}\text { [96] }(n=268) & 26(\mathrm{CL}) \\ & 10(\mathrm{BSA}) \\ {[19](n=50)} & 21\end{array}$

$r=0.42$

No relationship, but $r$-value not published

Paclitaxel

BSA dosing

[85] $(n=12)$

12 (free drug) 24 (CrEl)

Flat-fixed dosing

[85] $(n=12)$

[38] $(n=32)$

25 (free drug)

32 (CrEl)

Irinotecan

BSA dosing

[102] $(n=47)$

30

Flat-fixed dose

[102] $(n=26)$

Carboplatin

GFR dosing

[157] $(n=12)$

[100] $(n=10)$

20

27 (CL)

40 (GFR)

12 (BSA)

In cases where variability in AUC values has not been published, the variabilities in $\mathrm{CL}$ and $\mathrm{BSA}$ have been given. If $\mathrm{CL}$ is related to $\mathrm{BSA}$, the variability for these two factors would be expected to be similar. $n$, number of evaluable patients; AUC, area under the plasma concentration-time curve; $C_{s s}$, steady-state plasma concentration; CL, clearance; CrEL, Cremophor EL; CV, coefficient of variation; GFR, glomerular filtration rate. "Unless otherwise stated. †Average from three dose levels. groups, so despite the decreased variability in AUC, no clinical differences were observed. In a different study, fixed paclitaxel doses $(360 \mathrm{mg})$ were also given as $3 \mathrm{~h}$ infusions to evaluate any relationships between BSA and toxicity and/or PK, and PK and toxicity [38]. BSA showed an inverse correlation with paclitaxel AUC, but was not related to any measure of toxicity. Also, BSA did not correlate with the 'hours above $0.05 \mu \mathrm{mol} / \mathrm{l}^{\prime}(\mathrm{T}>0.05)$ paclitaxel threshold concentration, which had been related to toxicity previously and in the current study. Accordingly, the recommendation from this study was that the use of fixed doses should be considered for most cytotoxic drugs.

The inverse relationships between BSA and paclitaxel AUC observed in these studies may be an artefact caused by the drug formulation. Paclitaxel has an affinity for the formulation vehicle Cremophor EL (CrEL), a polyoxyethylated castor oil, which has a volume of distribution $\left(V_{D}\right)$ of about the volume of the blood compartment, and can alter paclitaxel accumulation in erythrocytes [87-89]. As total blood volume is related to BSA, the effect of BSA on the variability in paclitaxel exposure could potentially be due to this drug-vehicle association, which may exhibit schedule-dependent effects on paclitaxel PK $[85,89,90]$. In addition, paclitaxel is metabolised mainly by hepatic cytochrome P450 (CYP) 2C8 and CYP3A4 (in addition to P. glycoprotein [Pgp] excretion, see Drug Resistance section), for which metabolic capacities are not correlated with BSA [38]. Docetaxel is another drug for which studies on the effect of BSA dosing show controversial results. A retrospective analysis of six studies did not show any correlation between docetaxel clearance and BSA [79]. On the contrary, in a population PK model for docetaxel, hepatic function, $\alpha$-1-acidic glycoprotein (AAG) and BSA were the most important predictors for clearance [91]. However, hepatic function and AAG influenced clearance the most, and are probably of importance partly because of their correlation with CYP3A activity, discussed later in this paper, and also because docetaxel binds to AAG [91-94].

The relevance of BSA-individualised dosing has also been prospectively investigated for 5-FU, cisplatin, topotecan (oral and intravenous), etoposide, irinotecan and retrospectively for some additional drugs and investigational agents [16,19,21,26,79,95-102]. The BSA-dosing of anticancer drugs was not recommended in any of these studies, and in many cases, fixed dosing strategies or other alternatives for dosing were suggested instead (see Part II [42]).

Key Point

- Most studies have shown that BSA dosing of chemotherapy does not reduce PK variability.

\section{Factors Causing Potential Variability in Drug Exposure}

Given the complexity of drug clearance, drug-related toxicity and anti-tumour activity, it does not seem logical 
to adjust the drug dose for one single factor. This is particularly relevant when an association between the variability in effect and the factor in question has not been demonstrated, or the factor is likely to be calculated or measured incorrectly. Various factors are known to affect drug distribution and elimination in individuals, and can therefore all potentially influence the therapeutic and toxic effects of a drug (see Table 2). For example, for oral drugs, bioavailability is a clearly significant factor, and it seems irrational to use the BSA approach in this case. Also, fixed unit dose sizes of tablets preclude dose individualisation anyway. This section considers some of the key factors responsible for the variation in exposure of tumour and healthy tissues to drugs, and whether or not BSA is of value in normalising these.

\section{Organ Function and Body Size Measures}

Hepatic and renal functions are essential predictors of drug metabolism and excretion, and are normally taken into account when determining doses of various drugs for patients with known renal or hepatic impairment $[2,68,77,101,103]$. However, it is probable that the predicted/measured levels of organ function are only approximate. For example, GFR is not the only estimate of renal function relevant for the renal clearance of all drugs, because tubular secretion and re-absorption, the effects of concomitant drugs, urine $\mathrm{pH}$ and altered diuresis may also influence clearance [104]. However, for both renal and

Table 2 - Factors affecting drug exposure and some examples from published reports

\begin{tabular}{lc}
\hline Factors that may & Examples of specific \\
affect variability in & drugs affected \\
drug exposure & (where known)
\end{tabular}

Hepatic function [103]

Renal function [103]

BSA [62]

Obesity $[74,106]$

Body composition [78]

Nutritional status [2]

Enzyme expression/activity [2]

Drug resistance [46]

Drug-binding plasma proteins [2]

Gender [33]

Age $[33,103]$

Disease [2]

Prior or concomitant drugs [2]

Dosing schedule [2]

Dose intensity [152] hepatic function, studies have indicated that no dosage adjustments are needed unless the function of either organ is significantly reduced $[93,105]$.

As far as BSA is concerned, it seems unlikely that differences in body size affect cytotoxic drug distribution and elimination to a large extent, and body size may only be relevant for inter-species or infant-adult comparisons $[66,74]$. Studies of potential dosage adjustments for extreme BSA values have been suggested by some researchers recommending fixed dosage regimens, and statistically significant differences in clearance for patients with extreme BSA values have been observed, for example with cisplatin, but not for irinotecan $[38,96,101]$. It has been proposed that obesity can alter anti-cancer drug PK $[33,68,74,106]$. This can be exemplified by observations of increased AAG levels (suggesting a smaller free drug fraction for basic drugs), and an increase in $V_{D}$ for some lipophilic drugs in obese individuals [74]. Different findings have been made regarding the effects of obesity on hepatic phase I metabolism. For example, in a study by Baker et al. [93] obesity did not affect CYP3A activity. Obesity may, however, increase glucuronidation and sulphation, as well as GFR and tubular secretion [74,101,107]. Further studies on this subject would be of value, as obesity is an increasing problem and there is a wide variation in BW within cancer patient groups, with, for example, a high proportion of obese among breast cancer patients [76].

Although organ size may alter drug PK in obesity, differences in body mass and size are not necessarily related to the size of organs involved in drug elimination $[60,74]$. Even if BSA was proportional to liver or kidney size, this may not correlate to organ function. For example, hepatic volume is unlikely to correlate well with hepatic drug clearance due to the large variability in expression and/or activity of metabolising enzymes, in addition to variable blood flow to the organ [33]. Body size is not the only factor to consider, as actual body composition is probably more important. BSA- or BW-individualised drug dosing assumes a universal body composition, and infers a homogenous drug distribution in the body. However, a certain unit of weight, or volume, is not composed in the same way in different individuals. The proportion of different tissue types varies between individuals of the same body size. Body composition is also affected by gender and age, which can be exemplified by a loss of muscle tissue in older people and a higher proportion of adipose tissue in women $[68,72,78]$. These differences in body composition may be important for drugs where tissue distribution is dependent on physiochemical properties, such as lipophilicity. Also, increased BW in an individual is usually not due to the increase in one tissue type only [78]. Reilly and Workman [76] proposed a theoretical chemical body composition where the body is divided into fat mass and fat-free mass. Gusella et al. [99] found that after 5-FU bolus doses, fat-free mass and total body water were better predictors of 5-FU clearance and $V_{D}$, respectively, than both BW and BSA. Lean body mass is another body composition estimate, similar to fat-free mass, which has been shown to be both superior and inferior to BSA for

BSA, body surface area; CrEL, cremophor EL; 5-FU, 5-fluorouracil; 6-MP, 6-mercaptopurine. "Examples from reports discussed in this review.

5-FU [151], and others Cisplatin [96], 5-FU [142] and others Carboplatin [153] 
individualising cytotoxic drug doses. The use of lean body mass was a better predictor of epirubicin clearance, but was less satisfactory in the case of irinotecan $[24,78,101]$.

Acçounting for some of the body composition estimates discussed above could be meaningful in cytotoxic drug dose individualisation, but as with BSA, they are difficult to measure or estimate accurately. Examples of methods used to determine body composition include various formulae, tomography, ultrasound and bioelectrical impedance analysis $[78,99]$.

\section{Key Points}

- Hepatic and renal functions can affect drug clearance and, hence, drug exposure. However, it should be noted that methods used to estimate these may suffer from limited accuracy.

- Extreme BSA values, obesity and body composition may also affect chemotherapy drug exposure.

\section{Enzyme Activity}

Genetic polymorphisms in genes coding for drug metabolising enzymes, including the CYP enzymes, cause large differences in drug metabolism and PK [108]. CYP activity may be further altered by concomitant drug intake, pathological conditions, including cancer, and factors such as age, gender, diet, obesity and smoking [33,77,109-112]. For example, many naturally occurring chemicals can modulate CYP expression, as well as interact with Pgp, described in a later section [110]. The use of herbal medicines and dietary supplements containing phytochemicals is quite common among cancer patients. Many patients fail to disclose their use of supplements for various reasons, such as the belief that natural drugs are 'safer' than prescribed drugs, and that it is not necessary to inform their physicians $[93,110]$. The possible influence of alternative medicines, which are not subject to the rigorous testing required for conventional drugs, on CYPs and other drug metabolising enzymes, should be considered in the treatment of cancer.

The importance of common genetic variability is also well recognised. For example, hepatic CYP3A4 activity was measured using the ${ }^{14} \mathrm{C}-\mathrm{N}$-methyl-erythromycin breath test (ERMBT) in 21 sarcoma patients receiving docetaxel [92]. This phenotypic expression of CYP3A4 activity was found to vary more than 20 -fold, and docetaxel clearance varied nearly six-fold. The natural log for ERMBT accounted for $67 \%$ of the inter-patient variability in docetaxel clearance, and was a better predictor of clearance than, for example, serum alanine aminotransferase, albumin or AAG levels. Epirubicin is another drug for which correlations between PK measures and CYP functionality have been observed [31].

Baker et al. [93] studied the possible influence of four genetic variants of CYP3A4, two variants of CYP3A5, gender, age, body size measures, AAG concentration and hepatic function on CYP3A activity in 134 cancer patients, also using ERMBT to estimate CYP3A activity. The variables studied were selected on the premise that inflammatory response factors, such as $\mathrm{C}$-reactive protein and AAG, and large variations in AAG concentrations in cancer patients, may be associated with decreased hepatic CYP3A clearance. In this study, inter-patient CYP3A activity varied 14fold, but from the factors studied, it was only influenced by hepatic function combined with AAG concentration. Based on these results, the investigators concluded that CYP3A phenotyping (reflecting combined effects of genetic, endogenous and environmental factors) will probably provide more clinically relevant information than enzyme genotyping, a view supported by additional studies [113] Similarly, Ando et al. [109] considered the difference in enzyme activity between CYP3A4 genotypes in vitro as too small to explain the wide inter-individual variability in enzyme activity. A polymorphism in the CYP3A4 gene has, however, been associated with treatment-related leukaemia attributed to epipodophyllotoxins [114].

An example of a rare, but clinically significant, autosomal co-dominantly inherited pharmacogenetic syndrome is the deficiency of DPD, an enzyme that, as previously mentioned, catalyses the oxidation of 5-FU. There are varying degrees of deficiency, but the polymorphism was characterised after the appearance of a life-threatening toxicity (often the first symptom) in patients treated with 5-FU, where a complete DPD deficiency can be lethal [77,95,115-121]. Other examples of inheritable enzyme deficiencies relevant to cancer chemotherapy are those for thiopurine S-methyltransferase (TPMT), an enzyme metabolising 6-MP and uridine diphosphate glucuronyltransferase 1A1 (UGT1A1), which metabolises the irinotecan metabolite SN-38 [122-124]. Both deficiencies may alter drug/metabolite $\mathrm{PK}$, resulting in altered therapeutic effect and/or severe toxicity, which can be fatal $[122,125]$. Genetic variants of drug efflux proteins, for example Pgp (discussed below), and drug-binding plasma proteins, for example albumin and $A A G$, will also influence clinical outcomes. For example, the unbound fraction of highly bound drugs significantly influences drug clearance and will be affected by any change in binding protein expression or activity [33,61,126-128]. The use of enzyme activity and/or gene expression profiling in chemotherapy dose determination, using some of the examples mentioned above, is considered in Part II [42].

\section{Key Points}

- Altered expression or functionality of CYP isozymes can significantly affect drug-related toxicity and therapeutic response.

- CYP activity may also be altered by various factors, such as concomitant drugs, pathological conditions, age, gender, diet, obesity and smoking.

- Rare, but clinically important, genetic enzyme deficiencies include those for DPD, TPMT and UGT1A1, which can cause lethal toxicity in treatment with 5-FU, 6-MP and irinotecan, respectively.

\section{Drug Resistance}

Intrinsic or acquired tumour cell drug resistance, mentioned previously in this review, can be mediated by 
different mechanisms that result in the alteration of drug targets, for example binding sites in DNA, RNA or microtubules, changes in the expression or activity of proteins involved in drug metabolism and/or DNA replication and repair, or drug accumulation in acidic compartments such as lysosomes $[2,49,51,65,129,130]$. Cellular drug resistance can also be caused by decreased intracellular drug concentrations, as a result of alterations in plasma membrane phospholipids, changed levels of expression and/or activity of trans-membrane proteins, resulting in drug efflux (multidrug resistance [MDR]), or modified ion concentrations and/or intracellular $\mathrm{pH}[49,129]$. A widely studied form of MDR is due to the over-expression of, or mutations in, $A B C$ genes coding for ATPase membrane transporters that expel xenobiotics from the cell $[49,61,131]$. Examples are those of the human MDR gene family, including the MDR1 gene coding for Pgp and the close analogue MDR3 (also known as MDR2), the MDRassociated protein (MRP) gene family, and the breast cancer resistance protein (ABCG2), which can be expressed physiologically in various tissue types, and in many tumours $[46,49,61,128,131-134]$. Chemotherapy resistance is not a trivial issue. For example, in the management of breast cancer, studies have shown that over-expression of MDR1 can be expected in about $40-50 \%$ of primary tumours and at least $50 \%$ of metastatic tumours $[46,135]$.

Various Pgp inhibitors have been studied in an attempt to control MDR [136,137]. For example, CrEL, the previously mentioned solubiliser for paclitaxel, has been proposed as a modulator of Pgp-mediated MDR in vitro [89]. However, PK studies have suggested that $\mathrm{CrEL}$ is limited to the central plasma compartment, and it is therefore unlikely to reverse MDR in vivo $[89,90]$. R101933 is a Pgp inhibitor that has been given both orally and intravenously in combination with docetaxel, which is a substrate for Pgp $[136,137]$. Unlike various other Pgp inhibitors, R101933 does not seem to affect docetaxel PK through competitive inhibition of the drug metabolising enzyme CYP3A4. Pgp inhibition in vivo was confirmed by the fact that faecal excretion of unchanged docetaxel decreased from about $2.5 \%$ to less than $1 \%$ of the administered dose, an effect thought to be caused by the inhibition of intestinal Pgp and modification of the enterohepatic cycle. However, the actual inhibition of Pgp in tumour cells could be limited, because R101933 is highly protein bound $(98 \%)$, and the free concentration reaching tumour cells is probably low [136]. Whether humans can tolerate the simultaneous long-term inhibition of Pgp-related physiological functions in, for example, the heart or blood-brain barrier, is yet to be evaluated. For example, it is doubtful that Pgp inhibition in the bloodBrain barrier is harmless, as it probably influences the uptake of substances into the brain. Common side-effects of R101933 are drowsiness and somnolence [136,137], which may indicate either a direct or an indirect action on the central nervous system.

A detailed review of drug resistance efflux mechanisms is beyond the scope of this paper, but it is clearly a significant factor in treatment outcomes and the variability in response for a given drug dose.
Key Points

- Drug resistance is a common and serious problem in cancer chemotherapy and a potential confounding factor to the success of any dosing strategy.

- Chemotherapy drug resistance can be caused by either decreased intracellular drug concentrations or alterations in drug targets, and may therefore affect both tumour exposure and response.

\section{Gender, Age and Disease}

Concurrent diseases, nutritional status, the intrinsic sensitivity of normal tissue and tumour type, gender and age are other patient-related factors that may contribute to inter- and/or intra-individual variability in cytotoxic drug response $[1,2,4,23,39]$. Obviously, a patient's condition and performance status generally affect dose selection and, as a result, possibly drug exposure and/or response. Concurrent diseases that may alter drug elimination in addition to renal and hepatic impairment include respiratory, cardiovascular, gastrointestinal and endocrine diseases $[33,78,94]$. Gender- or age-dependent differences in clinical PK of drugs can be caused by differences in drug absorption, hepatic metabolism, renal elimination, organ function, organ blood flow or body composition $[33,97,138]$. After oral and intravenous administration of topotecan, a statistically significant increase in clearance $(38 \%)$ of topotecan lactone has been observed in males compared with females [97]. This difference was associated with the physiologically lower haematocrit value in females, which, partly through pre-clinical studies, proved to be a significant predictor of topotecan lactone clearance. However, topotecan is mainly cleared renally, and as relationships between haematocrit and renal function have been observed, renal function may partly explain this gender difference $[139,140]$. Observations have shown free cisplatin clearance to be significantly higher in men, again a difference that could not be explained by the gender difference in BSA alone [96].

\section{Key Points}

- Gender, age and disease can influence key physiological functions, including hepatic function, renal function and organ blood flow.

- Decisions concerning dose selection are often influenced by age, disease and performance status. Consideration of these factors will therefore also exert an indirect effect on drug exposure and dose intensity.

\section{Scheduling and Administration Sequence}

Variability in the clinical effects of cytotoxic drugs is also caused by differences in scheduling and the, route of administration. This can be exemplified by studies on paclitaxel administration in breast cancer. Comparisons of 3 weekly administrations, at varying doses $\left(135-250 \mathrm{mg} / \mathrm{m}^{2}\right)$ 
and schedules (1-96 h infusions), with weekly administration or prolonged continuous infusion, have indicated that the dose-limiting toxicity (neutropenia) is both dose and schedule dependent [141]. Infusion duration has also been shown to affect cisplatin and 5-FU clearance [96,130,142-144]. 5-FU exhibits non-linear PK, and its clearance is higher after infusion than after bolus administration [142]. The toxicity profile for $5-\mathrm{FU}$ is also schedulle dependent, and the tendency to cause, for example, palmar-plantar syndrome and stomatitis, is associated with the continuous infusion regimen $[145,146]$. Larsson et al. [142] compared 5-FU PK after bolus 'push-injections' ( $2 \mathrm{~min}$ ) with short infusions (20 min) of $500 \mathrm{mg} / \mathrm{m}^{2}$ doses in 14 colorectal cancer patients. Both the intra- and inter-individual variations in AUC were more pronounced after short infusion than with bolus, and the AUC values were significantly larger after bolus administration. Treatment effects and toxicities related to the same administration techniques were analysed retrospectively by the same investigators in 198 patients with colorectal cancer. Response rates were significantly higher after bolus administration (median $2 \mathrm{~min}$ ) compared with infusions (median $20 \mathrm{~min}$ ), and despite higher frequencies of leukocyte depletion and gastrointestinal toxicity after bolus administration, quality of life was improved. 5-FU scheduling has also, for example, been observed to be of importance in combinations with irinotecan [147]. The fact that there can be large differences in administration technique between different members of staff and clinics can therefore be of importance. What would be considered a bolus injection by one health professional would be considered as a short infusion by others $[142,143,148]$. For example, it has been observed that the same 5-FU dose was given over 2 , 15 and $30 \mathrm{~min}$ by different consultants in a single UK cancer centre [143]. Additionally, for drugs such as 5-FU and cisplatin with PK exhibiting circadian variation, the timing of drug administration can affect therapeutic response and/or toxicity profiles $[34,149,150]$.

Cancer patients are also usually treated with multiple therapies using a range of cytotoxic, analgesic and antiemetic drugs, and their drug exposure can be affected by both prior and concomitant treatments $[2,33]$. Explanations for this include MDR, effects on drug metabolising enzymes, and displacement from protein binding. Increased drug toxicity in pre-treated patients is another problem assumed to be due to the cumulative effects of some cytotoxic drugs $[2,6,14,29]$. In addition, there is a high risk of drug interactions, and consequently the administration sequence may be of clinical importance. For example, both paclitaxel and $\mathrm{CrEL}$ alone affect doxorubicin PK [89]. A study comparing adverse effects for doxorubicin and cyclophosphamide (AC) when given before or after therapy with paclitaxel and trastuzumab showed a higher incidence of cardiomyopathy when $A C$ is given first [12]. A further example is an interaction between methotrexate and 5-FU, where pre-treatment with methotrexate and leucovorin seems to modulate the clinical effect of 5-FU $[12,130,151]$.

\section{Key Points}

- Scheduling, administration route and administration sequence can all affect chemotherapy drug PK and therapeutic and toxic outcomes.

- It is unlikely that the schedules currently used in clinical practice are optimal.

- Chemotherapy schedules are open to different interpretation by different centres, for example, a 'slow bolus' given over $10 \mathrm{~min}$ in one centre may be given over $5 \mathrm{~min}$ in another.

\section{Dose Size and Intensity}

Dose size, dose intensity (cumulative dose/duration of treatment) and cumulative dose may affect the outcome of cytotoxic drug therapy [152-155]. The laboratory rationale supporting the logic of dose intensification, for example of alkylating agents, is mainly based on sigmoidal relationships between drug dose and cell kill. However, cancer cells in vivo do not necessarily respond in a similar way $[2,145]$. A universal agreement on the concept of dose intensity is lacking and as it is often defined in different ways in Uifferent trials, its influence on treatment outcomes can be difficult to study $[145,152,156]$. Frequently, only the intended drug doses are published, and not the actual doses given. The actual dose intensity is influenced by both patient intrinsic factors, such as bone marrow toxicity resulting in delayed or cancelled doses, and treatmentrelated factors, such as adequate dosing. Dose intensity is also based on the assumption that dose scheduling does not alter anti-tumour effect or toxicity, and that dose delay and dose reduction are of equal significance.

\section{Conclusions}

In 1958, Pinkel [62] concluded that 'surface area correlates well with those physiologic parameters that are measurable at present'. Current knowledge suggests that factors other than BSA probably contribute more to inter-patient variability in cytotoxic drug exposure and in treatment outcomes. The customary use of BSA in dose calculations may contribute to the omission of these factors, give a false sense of accuracy and introduce error. It is questionable whether all current cancer treatment strategies are near optimal, or even ethical. BSA should be used for allometric scaling purposes in phase I clinical trials, as the scaling of toxicity data from animals is important for selecting starting doses in man, but the gradual discontinuation of BSA-based dosing of cytotoxic drugs in clinical practice is seemingly justified. However, no simple or satisfactory method for cytotoxic drug dose calculation exists, and the introduction and evaluation of new approaches is not an easy process. When determining drug doses in clinical practice, it is not possible to account for, or even measure, all factors relevant for drug handling, and the fact that most anti-cancer drugs are rarely given as single-drug regimens complicates the analysis and optimisation of dosages and schedules. However, many of the current 
problems in cancer chemotherapy had been recognised as early as 1956 [65], and the fact that they have still not been solved may suggest that a larger part of research efforts should be spent on exploring what is the 'optimal use' for already marketed drugs. Many current doses and schedules in clinical use have probably not been developed based on what might be therapeutically optimal, but may have been dependent on extraneous or practical issues such as the 5 day working week. One of the reasons that these arguably 'less than ideal' practices have survived so long is that finding a better alternative with practical utility is not straightforward. Some of the options are discussed in Part II of this two-part series [42].

Author for correspondence: G. J. Sewell, Department of Pharmacy, Kingston University, Penrhyn Road, Kingston upon Thames, Surrey KT1 2EE, UK. Tel: +44-20-85477577; Fax: +44-2085477562; E-mail: g.j.sewell@kingston.ac.uk

Received 15 September 2006; received in revised form 4 October 2006; accepted 31 October 2006

\section{References}

1 Gurney H. Dose calculation of anticancer drugs: a review of the current practice and introduction of an alternative. $\mathrm{J} \mathrm{Clin}$ Oncol 1996;14:2590-2611.

2 Perry MC, editor. The chemotherapy source book. Baltimore: Williams and Wilkins, 1996.

3 Moore MJ, Erlichman C, Thiessen JJ, et al. Variability in the pharmacokinetics of cyclophosphamide, methotrexate and 5 fluorouracil in women receiving adjuvant treatment for breast cancer. Cancer Chemother Pharmacol 1994;33:472-476.

4 Pierga JY, Fumoleau P, Brewer Y, et al. Efficacy and safety of single agent capecitabine in pretreated metastatic breast cancer patients from the French compassionate use program. Breast Cancer Res Treat 2004;88:117-129.

5 McClish DK, Roberts JD. Phase I studies of weekly administration of cytotoxic agents: implications of a mathematical model. Invest New Drugs 2003;21:299-308.

6 Rivera E, Erder MH, Fridman M, Frye D, Hortobagyi GN. Firstcycle absolute neutrophil count can be used to improve chemotherapy-dose delivery and reduce the risk of febrile neutropenia in patients receiving adjuvant therapy: a validation study. Breast Cancer Res 2003;5:R114-R120.

7 Budman DR, Berry DA, Cirrincione CT, et al. Dose and dose intensity as determinants of outcome in the adjuvant treatment of breast cancer. J Natl Cancer Inst 1998;90: 1205-1211.

8 Bonadonna G, Valagussa P, Mioliterni A, Zambetti M, Brambilla C. Adjuvant cyclophosphamide, methotrexate, and fluorouracil in node-positive breast cancer. The results of 20 years follow-up. N Engl J Med 1995;332:901-906.

9 Cooper R, Kaanders JHAM. Biological surrogate end-points in cancer trials: potential uses, benefits and pitfalls. Eur J Cancer 2005;41:1261-1266.

10 Egorin MJ. Overview of recent topics in clinical pharmacology of anticancer agents. Cancer Chemother Pharmacol 1998;42: S22-S30.

11 Tonkin KS, Levin L, Powe J. Neither toxicity nor dose intensity of carboplatin is affected by glomerular filtration rate versus body surface area dose calculation in gynecologic malignancy. Int J Gynecol Cancer 1994;4:315-319.

12 Mokbel K, Kirkpatrick KL. Recent advances in breast cancer (Twenty-fourth San Antonio Breast Cancer Symposium, December, 2001). Curr Med Res Opin 2002;18:26-29.

13 Martin M. Platinum compounds in the treatment of advanced breast cancer. Clin Breast Cancer 2001;2:190-208.

14 Jodrell DI, Egorin MJ, Canetta RM, et al. Relationships between carboplatin exposure and tumour response and toxicity in patients with ovarian cancer. J Clin Oncol 1992; 10:520-528.

15 Sørensen BT, Strömgren A, Jakobsen P. Dose-toxicity relationship of carboplatin in combination with cyclophosphamide in ovarian cancer patients. Cancer Chemother Pharmacol 1991; 28:397-401.

16 Fety R, Rolland F, Barberi-Heyob M, et al. Clinical impact of pharmacokinetically-guided dose adaptation of 5-fluorouracil: results from a multicentric randomised trial in patients with locally advanced head and neck carcinomas. Clin Cancer Res 1998;4:2039-2045.

17 Evans WE, Relling MV, Rodman JH, Crom WR, Boyett JM, Pui C-H. Conventional compared with individualized chemotherapy for childhood acute lymphoblastic leukemia. N Engl $J$ Med 1998;338:499-505.

18 Desoize B, Marechal F, Cattan A. Clinical pharmacokinetics of etoposide during 120 hours continuous infusions in solid tumours. Br J Cancer 1990;62:840-841.

19 Schellens JHM, Ma J, Planting AST, et al. Relationship between the exposure to cisplatin, DNA-adduct formation in leucocytes and tumour response in patients with solid tumours. $\mathrm{Br} \mathrm{J}$ Cancer 1996;73:1569-1575.

20 Zamboni WC, D'Argenio DZ, Stewart CF, et al. Pharmacodynamic model of topotecan-induced time course of neutropenia. Clin Cancer Res 2001;7:2301-2308.

21 Loos WJ, Gelderblom H, Sparreboom A, Verweij J, de Jonge MJA. Inter- and intrapatient variability in oral topotecan pharmacokinetics: implications for body-surface area dosage regimens. Clin Cancer Res 2000;6:2685-2689.

22 Milano G, Roman P, Khater R, Frenay M, Renee N, Namer M. Dose versus pharmacokinetics for predicting tolerance to 5-day continuous infusion of 5-FU. Int J Cancer 1988;41:537-541.

23 Mathijssen RHJ, van Alphen RJ, Verweij J, et al. Clinical pharmacokinetics and metabolism of irinotecan (CPT-11). Clin Cancer Res 2001;7:2182-2194.

24 Cosolo WC, Morgan DJ, Seeman E, Zimet AS, MCKendrick JJ, Zalcberg JR. Lean body mass, body surface area and epirubicin kinetics. Anticancer Drugs 1994;5:293-297.

25 Danesi R, Fogli S, Gennari A, Conte P, Del Tacca M. Pharmacokinetic-pharmacodynamic relationships of the anthracycline anticancer drugs. Clin Pharmacokinet 2002;41:431-444.

26 Toffoli G, Corona G, Sorio R, et at. Population pharmacokinetics and pharmacodynamics of oral etoposide. $\mathrm{Br} J \mathrm{Clin}$ Pharmacol 2001;52:511-519.

27 Calvert AH, Newell DR, Gumbrell LA, et al. Carboplatin dosage: prospective evaluation of a simple formula based on renal function. J Clin Oncol 1989;7:1748-1756.

28 Ignoffo RJ, King R. Pharmaceutical care and the cancer patient. J Oncol Pharm Pract 1995;1:7-19.

29 Egorin $\mathrm{MJ}^{\circ}$, Jodrell DI. Utility of individualized carboplatin dosing albne and in combination regimens. Semin Oncol 1992; 19:132-138.

30 Minami H. A pointa line, or an area? Which is the most important in the pharmacological analysis of cancer chemotherapy? J Clin Oncol 2005;23:405-406. 
31 Gurney HP, Ackland S, Gebski V, Farrell G. Factors affecting epirubicin pharmacokinetics and toxicity: evidence against using body-surface area for dose calculation. J Clin Oncol 1998;16:2299-2304.

32 Sandstrom $M$, Lindman $H$, Nygren P, Lidbrink E, Bergh J, Karlssoh MO. Model describing the relationship between pharmacokinetics and hematologic toxicity of the epirubicin-docetaxel regimen in breast cancer patients. $J$ Clin Oncol 2005;23:413-421.

33 Rowland M, Tozer TN. Clinical pharmacokinetics, concepts and applications. Philadelphia: Lippincott Williams and Wilkins, 1995.

34 Takimoto $\mathrm{CH}$, Yee LK, Venzon DJ, et al. High inter- and intrapatient variation in 5-fluorouracil plasma concentrations during a prolonged drug infusion. Clin Cancer Res 1999;5: 1347-1352.

35 Reigner B, Watanabe T, Schuller J, et al. Pharmacokinetics of capecitabine (Xeloda) in Japanese and Caucasian patients with breast cancer. Cancer Chemother Pharmacol 2003;52: 193-201.

36 Collins JM, Zaharko DS, Dedrick RL, Chabner BA. Potential roles for preclinical pharmacology in phase I clinical trials. Cancer Treat Rep 1986;70:73-80.

37 Gallo JM, Vicini P, Orlansky A, et al. Pharmacokinetic modelpredicted anticancer drug concentrations in "human tumors. Clin Cancer Res 2004;10:8048-8058.

38 Miller AA, Rosner GL, Egorin MJ, Hollis D, Lichtman SM, Ratain MJ. Prospective evaluation of body surface area as a determinant of paclitaxel pharmacokinetics and pharmacodynamics in women with solid tumors: Cancer and Leukemia Group B Study 9763. Clin Cancer Res 2004;10:8325-8331.

39 Groninger E, Proost JH, de Graaf SSN. Pharmacokinetic studies in children with cancer. Crit Rev Oncol Hematol 2004;52: 173-197.

40 Bressolle F, Bromet-Petit M, Audran M. Validation of liquid chromatographic and gas chromatographic methods. Applications to pharmacokinetics. J Chromatogr B Biomed Sci Appl 1996;686:3-10.

41 Watson GW. Pharmaceutical analysis. London: Harcourt, 1999.

42 Kaestner SA, Sewell GJ. Chemotherapy dosing part II: Alternative approaches and future prospects. Clin Oncol in press.

43 Ratain MJ, Schilsky RL, Conley BA, Egorin MJ. Pharmacodynamics in cancer therapy. J Clin Oncol 1990;8:1739-1753.

44 Michael M, Doherty MM. Tumoral drug metabolism: overview and its implications for cancer therapy. J Clin Oncol 2005;23: 205-229.

45 Brown JM, Giaccia AJ. The unique physiology of solid tumours: opportunities (and problems) for cancer therapy. Cancer Res 1998;58:1408-1416.

46 Lehnert $M$. Chemotherapy resistance in breast cancer. Anticancer Res 1998;18:2225-2226.

47 Aboagye EO, Saleem A, Cunningham VJ, Osman S, Price PM. Extraction of 5 -fluorouracil by tumor and liver: a noninvasive positron emission tomography study of patients with gastrointestinal cancer. Cancer Res 2001;61:4937-4941.

48 Tsukamoto $Y$, Kato $Y$, Ura M, et al. A physiologically based pharmacokinetic analysis of capecitabine, a triple prodrug of 5-FU, in humans: the mechanism for tumor-selective accumulation of 5-FU. Pharm Res 2001;18:1190-1202.

49 Simon SM, Schindler M. Cell biological mechanisms of multidrug resistance in tumours. Proc Natl Acad Sci (Med Sci) 1994;91:3497-3504.

50 Tannock IF, Lee CM, Tunggal JK, Cowan DSM, Egorin MJ. Limited penetration of anticancer drugs through tumor tissue: a potential cause of resistance of solid tumors to chemotherapy. Clin Cancer Res 2002;8:878-884.

51 Eytan GD, Regev R, Oren G, Assaraf YG. The role of passive transbilayer drug movement in multidrug resistance and its modulation. J Biol Chem 1996;271:12897-12902.

52 Presant CA, Wolf W, Waluch V, et al. Association of intratumoral pharmacokinetics of fluorouracil with clinical response. Lancet 1994;343:1184-1187.

53 Price P, Griffiths J. Tumour pharmacokinetics? - we need to know. Lancet 1994;343:1174-1175.

54 Wolf W, Presant CA. Tumor-based pharmacokinetics has greater significance for anticancer drugs than does blood based pharmacokinetics. Clin Pharmacol Ther 2004;76:508.

55 Wolf W, Presant CA, Waluch V. ${ }^{19} \mathrm{~F}$-MRS studies of fluorinated drugs in humans. Adv Drug Deliv Rev 2000;41:55-74.

56 Presant CA, Wolf W, Waluch V, Wiseman CL, Weitz I, Shani J. Enhancement of fluorouracil uptake in human colorectal and gastric cancers by interferon or by high-dose methotrexate: an in vivo human study using noninvasive ${ }^{19} \mathrm{~F}$-magnetic resonance spectroscopy. J Clin Oncol 2000;18:255-261.

57 Schlemmer H-P, Becker M, Bachert P, et al. Alterations of intratumoral pharmacokinetics of 5 -fluorouracil in head and neck carcinoma during simultaneous radiochemotherapy. Cancer Res 1999;59:2363-2369.

58 Dowell JA, Sancho AR, Anand D, Wolf W. Noninvasive measurements for studying the tumoural pharmacokinetics of platinum anticancer drugs in solid tumors. Adv Drug Deliv Rev 2000;41:111-126.

59 Presant CA, Jacobson J, Wolf W, Waluch V, Weitz IC, Macdonald JS. Does leucovorin alter the intratumoural pharmacokinetics of 5-fluorouracil (5-FU)? A Southwest Oncology Group Study. Invest New Drugs 2002;20:369-376.

60 Desoize B, Robert J. Individual dose adaptation of anticancer drugs. Eur J Cancer 1994;30A:844-851.

61 Scheffer GL, Kool M, Heijn M, et al. Specific detection of multidrug resistance proteins MRP1, MRP2, MRP3, MRP5 and MDR3 P-glycoprotein with a panel of monoclonal antibodies. Cancer Res 2000;60:5269-5277.

62 Pinkel D. The use of body surface area as a criterion of drug dosage in cancer chemotherapy. Cancer Res 1958;18:853-856.

63 Dooley MJ, Poole SG. Poor correlation between body surface area and glomerular filtration rate. Cancer Chemother Pharmacol 2000;46:523-526.

64 Pinkel D. Cancer chemotherapy and body surface area. J Clin Oncol 1998; 16:3714-3715.

65 Farber S, Toch R, Sears EM, Pinkel D. Advances in chemotherapy of cancer in man. Adv Cancer Res 1956;4:1-71.

66 Freireich EJ, Gehan EA, Rall DP, Schmidt LH, Skipper HE. Quantitative comparison of toxicity of anticancer agents in mouse, rat, hamster, dog, monkey, and man. Cancer Chemother Rep 1966;50:219-244.

67 Martin AD, Drinkwater DT, Clarys JP. Human body surface area: validation of formulae based on a cadaver study. Hum Biol 1984;56:475-488.

68 Reilly JJ, Workman P. Normalisation of anti-cancer drug dosage using body weight and surface area: is it worthwhile? Cancer Chemother Pharmacol 1993;32:411-418.

69 Mitchell D, Strydom NB, van Graan $\mathrm{CH}$, van der Walt WH. Human surface area: comparison of the du Bois formula with direct photometric measurement. Pflügers Arch 1971;325: 188-190.

70 Du Bois D, Du Bois EF. A formula to estimate the approximate surface area if height and weight be known. Arch Intern Med 1916;17:863-871. 
71 Gehan EA, George SL. Estimation of human body surface area from height and weight. Cancer Chemother Rep 1970;54:225-235.

72 Newell DR. Getting the right dose in cancer chemotherapy - time to stop using surface area? Br J Cancer 2002;86: 1207-1208.

73 Cancer Care Ontario. Calculation of body surface area (BSA): Appendix 4. http://www.cancercare.on.ca/index_drugFormu laryappendix4.htm. 15 September 2006.

74 Baker SD, Grochow LB, Donehower RC. Should anticancer drug doses be adjusted in the obese patient? J Natl Cancer Inst 1995;87:333-334.

75 Lesar TS. Errors in the use of medication dosage equations. Arch Pediatr Adolesc Med 1998;152:340-344.

76 Reilly JJ, Workman P. Is body composition an important variable in the pharmacokinetics of anticancer drugs? Cancer Chemother Pharmacol 1994;34:3-13.

77 Veal GJ, Coulthard SA, Boddy AV. Chemotherapy individualization. Invest New Drugs 2003;21:149-156.

78 Morgan DJ, Bray KM. Lean body mass as a predictor of drug dosage. Implications for drug therapy. Clin Pharmacokinet 1994;26:292-307.

79 Baker SD, Verweij J, Rowinsky EK, et al. Role of body surface area in dosing of investigational anticancer agents in adults, 1991-2001. J Natl Cancer Inst 2002;94:1883-1888.

80 Miller AA. Body surface area in dosing anticancer agents: scratch the surface! J Natl Cancer Inst 2002;94:1822-1823.

81 Grochow LB, Baraldi C, Noe D. Is dose normalization to weight or body surface area useful in adults? J Natl Cancer Inst 1990; $82: 323-325$.

82 Sawyer M, Ratain MJ. Body surface area as a determinant of pharmacokinetics and drug dosing. Invest New Drugs 2001;19: $171-177$.

83. Bleyer WA. A flat dose for all adult [sic] patients. J Clin Oncol 1998;16:3715.

84 Dobbs NA, Twelves CJ. What is the effect of adjusting epirubicin doses for body surface area? Br J Cancer 1998;78: 662-666.

85 Smorenburg $\mathrm{CH}$, Sparreboom A, Bontenbal M, Stoter G, Nooter N, Verweij J. Randomized cross-over evaluation of body-surface area-based dosing versus flat-fixed dosing of paclitaxel. J Clin Oncol 2003;21:197-202.

86 Egorin MJ. Horseshoes, hand grenades, and body-surface-areabased dosing: aiming for a target. J Clin Oncol 2003;21: $182-183$

87 Kearns CM. Pharmacokinetics of the taxanes. Pharmacotherapy 1997;17:105S-109S.

88 Smith IC, Hutcheon AW, Heys SD. Current and potential chemotherapeutic agents used for induction chemotherapy in the treatment of breast cancer. Curr Pharm Des 2000;6: $327-343$.

89 Sparreboom A, van Zuylen L, Brouwer E, et al. Cremophor ELmediated alteration of paclitaxel distribution in human blood: clinical pharmacokinetic implications. Cancer Res 1999;59: 1454-1457.

90 van Zuylen L, Gianni L, Verweij J, et al. Inter-relationships of paclitaxel disposition, infusion duration and cremophor EL kinetics in cancer patients. Anticancer Drugs 2000;11: $331-337$.

91 Bruno R, Vivler N, Vergniol JC, De Phillips SL, Montay G, Sheiner LB. A population pharmacokinetic model for docetaxel (Taxotere): model building and validation. J Pharmacokinet Biopharm 1996;24:153-172.

92 Hirth J, Watkins PB, Strawderman M, Schott A, Bruno R, Baker LH. The effect of an individual's cytochrome CYP3A4 activity on docetaxel clearance. Clin Cancer Res 2000;6: 1255-1258.

93 Baker SD, van Schaik RHN, Rivory LP, et al. Factors affecting cytochrome P-450 3A activity in cancer patients. Clin Cancer Res 2004; 10:8341-8350.

94 van den Bongard HJGD, Mathôt RAA, Beijnen JH, Schellens JHM. Pharmacokinetically guided administration of chemotherapeutic agents. Clin Pharmacokinet 2000;39: 345-367.

95 Gamelin E, Boisdron-Celle M, Guerin-Meyer V, et al. Correlation between uracil and dihydrouracil plasma ratio, fluorouracil (5-FU) pharmacokinetic parameters, and tolerance in patients with advanced colorectal cancer: a potential interest for predicting 5-FU toxicity and determining optimal 5-FU dosage. J Clin Oncol 1999;17:1105-1110.

96 de Jongh FE, Verweij J, Loos WJ, et al. Body-surface areabased dosing does not increase accuracy of predicting cisplatin exposure. J Clin Oncol 2001;19:3733-3739.

97 Loos WJ, Gelderblom HJ, Verweij J, Brouwer E, de Jonge MJ, Sparreboom A. Gender-dependent pharmacokinetics of topotecan in adult patients. Anticancer Drugs 2000;11:673-680.

98 Ratain MJ. Body-surface area as a basis for dosing of anticancer agents: science, myth, or habit? J Clin Oncol 1998; $16: 2297-2298$.

99 Gusella M, Toso S, Ferrazzi E, Ferrari M, Padrini R. Relationships between body composition parameters and fluorouracil pharmacokinetics. J Clin Pharmacol 2002;54:131-139.

100 Chatelut E, Chevreau C, Brunner V. A pharmacologically guided phase I study of carboplatin in combination with methotrexate and vinblastine in advanced urothelial cancer. Cancer Chemother Pharmacol 1995;35:391-396.

101 Mathijssen RHJ, Verweij J, de Jonge MJA, Nooter K, Stoter G, Sparreboom A. Impact of body-size measures on irinotecan clearance: alternative dosing recommendations. J Clin Oncol 2002;20:81-87.

102 de Jong FA, Mathijssen RHJ, Xie R, Verweij J, Sparreboom A. Flat-fixed dosing of irinotecan: influence on pharmacokinetic and pharmacodynamic variability. Clin Cancer Res 2004;10: 4068-4071.

103 COIN guidelines. Clin Oncol (R Coll Radiol) 2001;13:S216-S248.

104 Tett SE, Kirkpatrick CMJ, Gross AS, McLachlan AJ. Principles and clinical application of assessing alterations in renal elimination pathways. Clin Pharmacokinet 2003;42: 1193-1211.

105 Takimoto $\mathrm{CH}$, Remick SC, Sharma S, et al. Dose-escalating and pharmacological study of oxaliplatin in adult cancer patients with impaired renal function: a National Cancer Institute Organ Dysfunction Working Group study. J Clin Oncol 2003;21: 2664-2672.

106 Portugal RD. Obesity and dose individualization in cancer chemotherapy: the role of body surface area and body mass index. Med Hypotheses 2005;65:748-751.

107 Chagnac A, Weinstein T, Korzets A, Ramadan E, Hirsch J, Gafter U. Glomerular hemodynamics in severe obesity. Am J Physiol Renal Physiol 2000;278:F817-F822.

108 Nagasubramanian R, Innocenti F, Ratain MJ. Pharmacogenetics in cancer treatment. Annu Rev Med 2003;54:437-452.

109 Ando $Y$, Tateishi T, Sekido Y, et al. Modification of elinical presentation of prostate tumors by a novel genetic variant in CYP3A4. N Natl Cancer Inst 1999;91:1587-1590.

110 loannides C. Pharmacokinetic interactions between herbal remedies and medicinal drugs. Xenobiotica 2001;32:451-478.

111 Singh BN. Effects of food on clinical pharmacokinetics. Clin Pharmacokinet 1999;37:213-255. 
112 Downie D, McFadyen MCE, Rooney PH, et al. Profiling cytochrome $P 450$ expression in ovarian cancer: identification of prognostic markers. Clin Cancer Res 2005;11:7369-7375.

113 Lepper ER, Baker SD, Permenter M, et al. Effect of common CYP3A4 and CYP3A5 variants on the pharmacokinetics of the cytochrome $P 450$ 3A phenotyping probe midazolam in cancer patients. Clin Cancer Res 2005;11:7398-7404.

114 Félix CA, Walker AH, Lange BJ, et al. Associatiốn of CYP3A4 genotype with treatment-related leukemia. ProcNatl Acad SCi USA 1998;95:13176-13181.

115 Mattison LK, Ezzeldin H, Carpenter M, Modak A, Johnson MR, Diasio RB. Rapid identification of dihydropyrimidine dehydrogenase deficiency by using a novel $2 \cdot{ }^{13} \mathrm{C}$-uracil breath test. Clin Cancer Res 2004; 10:2652-2658.

116 van Kuilenburg ABP, Muller EW, Haasjes J, et al. Lethal outcome of a patient with a complete dihydropyrimidine dehydrogenase (DPD) deficiency after administration of 5 . fluorouracil: frequency of the common IVS14+1G > A mutation causing DPD deficiency. Clin Cancer Res 2001;7: $1149-1153$.

117 Baccanari DP, Davis ST, Knick VC, Spector T. 5-Ethynyluracil (776C85): a potent modulator of the pharmacokinetics and antitumor efficacy of 5-fluorouracil. Proc Natl Acad Sci USA 1993;90:11064-11068.

118 Milano G, Etienne MC, Pierrefite V, Barberi-Heyob M, DeporteFety R, Renée N. Dihydropyrimidine dehydrogenase deficiency and fluorouracil-related toxicity. $\mathrm{Br} J$ Cancer 1999;79: $627-630$.

119 Ogura K, Ohnuma T, Minamide Y, et al. Dihydropyrimidine dehydrogenase activity in 150 healthy Japanese volunteers and identification of novel mutations. Clin Cancer Res 2005;11: 5104-5111.

120 Diasio RB, Beavers TL, Carpenter JT. Familial deficiency of dihydropyrimidine dehydrogenase. J Clin Invest 1988;81: 47-51.

121 Fleming RA, Milano GA, Gaspard MH, et al. Dihydropyrimidine dehydrogenase activity in cancer patients. Eur J Cancer 1993; 29A:740-744.

122 Relling MV, Hancock ML, Rivera GK, et al. Mercaptopurine therapy intolerance and heterozygosity at the thiopurine $S$ methyltransferase gene locus. I Natl Cancer Inst 1999;91: 1983-1985.

123 Black AJ, McLeod HL, Capell HA, et al. Thiopurine methyltransferase genotype predicts therapy-limiting severe toxicity from azathioprine. Ann Intern Med 1998;129:716-718.

124 Ando $Y$, Saka $H$, Ando $M$, et al. Polymorphisms of UDP. glucuronosyltransferase gene and irinotecan toxicity: a pharmacogenetic analysis. Cancer Res 2000;60:6921-6926.

125 Gearry RB, Barclay ML, Roberts RL, et al. Thiopurine methyltransferase and 6-thioguanine nucleotide measurement: early experience of use in clinical practice. Intern Med J 2005;35:580-585.

126 Rappa G, Lorico A, Liu M-C, et al. Overexpression of the multidrug resistance genes MDR1, MDR3 and MRP in L1210 leukemia cells resistant to inhibitors of ribonucleotide reductase. Biochem Pharmacol 1997;54:649-655.

127 Chao CC, Ma CM, Lin-Chao S. Co-amplification and overexpression of two mdr genes in a multidrug-resistant human colon carcinoma cell line. FEBS Lett 1991;291:214-218.

128 Smith AJ, van Helvoort A, van Meer G, et al. MDR3 P. glycoprotein, a phosphatidylcholine translocase, transports several cytotoxic drugs and directly interacts with drugs as judged by interference with nucleotide trapping. $J$ Biol Chem 2000;275:23530-23539.
129 Zaman GJR, Flens MJ, Van Leusden MR, et al. The human multidrug resistance-associated protein MRP is a plasma membrane drug efflux pump. Proc Natl Acad Sci (Med Sci) 1994;91:8822-8826.

130 Diasio RB, Harris BE. Clinical pharmacology of 5-fluorouracil. Clin Pharmacokinet 1989;16:215-237.

131 Hoffmeyer S, Burk O, von Richter O, et al. Functional polymorphisms of the human multidrug resistance gene: multiple sequence variations and correlation of one allele with P-glycoprotein expression and activity in vivo. Proc Natl Acad Sci USA 2000;97:3473-3478.

132 Alexandrova R. Multidrug resistance and P-glycoprotein. EPP 1998;1:62-66.

133 Borst $P$, Evers R, Kool M, Wijnholds J. A family of drug transporters: the multidrug resistance-associated proteins. J Natl Cancer Inst 2000;92:1295-1302.

134 Sugimoto $\mathrm{Y}$, Tsukahara S, Ishikawa E, Mitsuhashi J. Breast cancer resistance protein: molecular target for anticancer drug resistance and pharmacokinetics/pharmacodynamics. Cancer Sci 2005;96:457-465.

135 Saeki T, Tsuruo T, Sato W, Nishikawa K. Drug resistance in chemotherapy for breast cancer. Cancer Chemother Pharmacol 2005;56(Suppl 1):S84-589.

136 van Zuylen L, Sparreboom A, van der Gaast A, et al. Disposition of docetaxel in the presence of P-glycoprotein inhibition by intravenous administration of R101933. Eur J Cancer 2002;38: 1090-1099.

137 van Zuylen L, Sparreboom A, van der Gaast A, et al. The orally administered P-glycoprotein inhibitor R101933 does not alter the plasma pharmacokinetics of docetaxel. Clin Cancer Res 2000;6:1365-1371.

138 Wildiers H, Highley MS, de Bruijn EA, van Oosterom AT. Pharmacology of anticancer drugs in the elderly population. Clin Pharmacokinet 2003;42:1213-1242.

139 Herben VMM, ten Bokkel Huinink WW, Beijnen JH. Clinical pharmacokinetics of topotecan. Clin Pharmacokinet 1996;31: 85-102.

140 Hsu C-Y, Bates DW, Kuperman GJ, Curhan GC. Relationship between hematocrit and renal function in men and women. Kidney Int 2001;59:725-731.

141 Perez EA, Hartmann LC. Paclitaxel and carboplatin for advanced breast cancer. Semin Oncol 1996;23:41-45.

142 Larsson P-A, Carlsson G, Gustavsson B, Graf W, Glimelius B. Different intravenous administration techniques for 5 -fluorouracil. Acta Oncol 1996;35:207-212.

143 Young AM, Daryanani S, Kerr DJ. Can pharmacokinetic monitoring improve clinical use of fluorouracil? Clin Pharmacokinet 1999;36:391-398.

144 Malet-Martino M, Martino R. Clinical studies of three oral prodrugs of 5-fluorouracil (capecitabine, UFT, S-1): a review. Oncologist 2002;7:288-323.

145 Leonard RCF. The importance of dose and schedule in cancer chemotherapy: breast cancer. Anticancer Drugs 1995;6: $17-27$.

146 Cristofanilli M, Hortobagyi GN. New horizons in treating metastatic disease. Clin Breast Cancer 2001;1:276-287.

147 Teufel A, Steinmann S, Siebler J, et al. Irinotecan plus folinic acid/continuous 5-fluorouracil as simplified bimonthly FOLFIRI regimen for first-line therapy of metastatic colorectal cancer. BMC Cancer 2004;4:38. http://www. biomedcentral.com/1471. 2407/4/38.

148 Taxis K, Barber N. Ethnographic study of incidence and severity of intravenous drug errors. $\mathrm{Br}$ Med J 2003;326: 684-687. 
149 Li XM, Tanaka K, Sun J, et al. Preclinical relevance of dosing time for the therapeutic index of gemcitabine-cisplatin. $\mathrm{Br} \mathrm{J}$ Cancer 2005;92:1684-1689.

150 Milano G, Chamorey A-L. Clinical pharmacokinetics of 5-fluorouracil with consideration of chronopharmacokinetics. Chronobiol Int 2002;19:177-189.

151 Tomlinson SK, Melin SA, Higgs V, et al. Schedule-selective biochemical modulation of 5 -fluorouracil in advanced colorectal cancer - a phase II study. BMC Cancer 2002;2:9. http://www.biomedcentral.com/1471-2407/2/9.

152 Hryniuk W. Dosage parameters in chemotherapy of breast cancer. Breast Dis 2001;14:21-30.

153 Alberts DS, Garcia DJ. Total platinum versus platinum dose intensification in ovarian cancer treatment. Semin Oncol 1994; 21:11-15.
154 Braess J, Fiegl M, Lorenz I, Waxenberger K, Hiddemann W. Modeling the pharmacodynamics of highly schedule-dependent agents: exemplified by cytarabine-based regimens in acute myeloid leukemia. Clin Cancer Res 2005;11:7415-7425.

155 Seidman AD. Current status of dose-dense chemotherapy for breast cancer. Cancer Chemother Pharmacol 2005;56(Suppl 1): S78-S83.

156 Ottevanger PB, De Mulder PHM, Grol RPTM, Van Lier H, Beex LVAM. Effects of quality of treatment on prognosis in primary breast cancer patients treated in daily practice. Anticancer Res 2002;22:459-466.

157 Siddiqui N, Boddy AV, Thomas HD, et al. A clinical and pharmacokinetic study of the combination of carboplatin and paclitaxel for epithelial ovarian cancer. Br J Cancer 1997;75: 287-294. 